\title{
Editorial
}

\section{Does any specific infection cause Kawasaki disease?}

\author{
Dong Seok Lee, MD, PhD
}

Department of Pediatrics, Dongguk University Gyeongju Hospital, Dongguk University College of Medicine, Gyeongju, Korea

Kawasaki disease (KD) is an acute self-limited vasculitis of unknown etiology that occurs predominantly in infants and children. The etiology of this disease remains a major pediatric mystery. Nonetheless, the self-limited clinical findings and generally nonrecurring nature of this febrile illness are highly suggestive of an infection rather than an autoimmune process. ${ }^{11}$

Numerous reports confirming viral and bacterial infections associated with KD outbreaks have been reported. ${ }^{2)}$ However, multiple investigations over several decades have demonstrated that no known unique infectious agent is closely related with $\mathrm{KD}$ etiology. ${ }^{1,3,4)}$

Taken together, many epidemiologic and clinical findings best support the hypothesis that $\mathrm{KD}$ is caused by a very common but unidentified infectious agent resulting in KD children with an underlying genetic predisposition.

Early studies of isolation of superantigen-producing bacteria or selective expansion of V $\beta$ family T-cell receptor suggested group A Streptococcus or Staphylococcus aureus as a powerful cause of $\mathrm{KD},{ }^{5,6}$ However, several subsequent papers reported no significant difference in superantigens between $\mathrm{KD}$ patients and controls. ${ }^{7)}$ Thus, the current understanding of the immune response favors the classic antigen that is protective against repeated exposure in most patients. ${ }^{1,3)}$

The recently published article entitled "High antistreptolysin 0 (ASO) titer is associated with coronary artery lesions in patients with Kawasaki disease" was interesting. ${ }^{8}$ The authors found that high ASO titers showed higher rates of a severe clinical course or coronary artery lesions (CALs). This is a very interesting results, because it has not been clearly demonstrated that a specific infection causes CALs in KD. However, there appears to be insufficient evidence to determine the acute infection of group A Streptococcus. Additionally, specific examinations such as throat culture, rapid antigen test, or other streptococcal antibody tests may be needed to determine the timing of infection. Analyses of whether patients had already known high risk factors or high ASO levels acted as risk factors are also needed since no reports to date have examined whether a high ASO increases the risk in KD patients. But detailed evaluation of group A streptococcal infection is required in future $\mathrm{KD}$ patients.

Another interesting topic is that if infectious diseases are identified, intravenous gamma globulin (IVIG) resistance or CALs may increase in KD patients.

According to one report, the simultaneous infection of group A Streptococcus in KD patients showed no difference in treatment response or CAL rate. ${ }^{5)}$ A single-center retrospective study was performed to determine the effect of coincident infection (including streptococcal infection) at the time of $\mathrm{KD}$ diagnosis on treatment response and coronary artery outcomes. As a result, a broad spectrum of infectious agents was found, but infections at the time of KD diagnosis were not statistically significantly associated with IVIG treatment response or coronary artery outcomes compared to those of patients without infections, even after the adjustment for other factors that may influence CALs. ${ }^{2)}$ Based on these results, it is believed that there are no unique infections in KD patients that respond particularly poorly to IVIG treatment or cause CALs.

Recent reports suggested the importance of viral infection in KD-related infectious diseases.
Corresponding author: Dong Seok Lee, MD, PhD Department of Pediatrics, Dongguk University Gyeongju Hospital, Dongguk University College of Medicine, 87 Dongdaero, Gyeongju 38067, Korea Tel: +82-54-770-8255

Fax: +82-54-770-8378

E-mail: Ids117@dongguk.ac.kr

https://orcid.org/0000-0001-9542-8250

Received: 12 February, 2019

Revised: 25 March, 2019

Accepted: 3 May, 2019
Copyright (C) 2019 by The Korean Pediatric Society

This is an open-access article distributed under the terms of the Creative Commons Attribution NonCommercial License (http://creativecommons.org/ licenses/by-nc/4.0/) which permits unrestricted noncommercial use, distribution, and reproduction in any medium, provided the original work is properly cited. 
Failure to respond to antibiotic therapy, a common susceptible age, specific seasonality, and the similar spread pattern of viral illness in patients with KD makes a viral etiology more likely than a bacterial one. ${ }^{1,3)}$

Moreover, the prevalence of CD8T cells and the upregulation of cytotoxic T cells and interferon pathway genes in the coronary arteries of children who have died of KD are highly suggestive of a viral etiology. ${ }^{3)}$ The molecular analysis of the oligoclonal immunoglobulin A response in acute KD led to the production of synthetic $\mathrm{KD}$ antibodies that identify RNA-containing cytoplasmic inclusion bodies in acute KD ciliated bronchial epithelial tissues. Light and electron microscopic observations showed that the inclusion bodies are consistent with aggregates of viral proteins and nucleic acids. ${ }^{9}$ These biochemical and pathological features increase the likelihood of a viral infection as the cause of $\mathrm{KD}$.

In conclusion, although the cause of $\mathrm{KD}$ remains to be elucidated, it is believed that infectious diseases are the most likely. Although no solitary causative infectious agents have been discovered to date, studies should continue to determine the etiology of KD. These efforts will bring novel strategies for the treatment and prognosis of $\mathrm{KD}$ patients in the near future.

\section{Conflicts of interest}

No potential conflicts of interest relevant to this article was reported.

\section{References}

1. Rowley AH. Is Kawasaki disease an infectious disorder? Int J Rheum Dis 2018;21:20-5.

2. Benseler SM, McCrindle BW, Silverman ED, Tyrrell PN, Wong J, Yeung RS. Infections and Kawasaki disease: implications for coronary artery outcome. Pediatrics 2005;116:e760-6.

3. Rowley AH, Shulman ST. The epidemiology and pathogenesis of Kawasaki disease. Front Pediatr 2018;6:374.

4. McCrindle BW, Rowley AH, Newburger JW, Burns JC, Bolger AF, Gewitz M, et al. Diagnosis, treatment, and long-term management of Kawasaki disease: a scientific statement for health professionals from the American Heart Association. Circulation 2017;135:927-99.

5. Cox F, Foshee W, Miller J Jr, Moore S. Simultaneous Kawasaki disease and group A streptococcal pharyngitis. Clin Pediatr (Phila) 1993; 32:48-50.

6. Matsubara K, Fukaya T. The role of superantigens of group A Streptococcus and Staphylococcus aureus in Kawasaki disease. Curr Opinion Infect Dis 2007;20:298-303.

7. Morita A, Imada Y, Igarashi H, Yutsudo T. Serologic evidence that streptococcal superantigens are not involved in the pathogenesis of Kawasaki disease. Microbiol Immunol 1997;41:895-900.

8. Min DE, Kim DH, Han MY, Cha SH, Yoon KL. High antistreptolysin 0 titer is associated with coronary artery lesions in patients with Kawasaki disease. Korean J Pediatr 2018 Nov 7 [Epub]. https://doi.org/ 10.3345/kjp.2018.06989.

9. Rowley AH, Baker SC, Shulman ST, Garcia FL, Fox LM, Kos IM, et al. RNA-containing cytoplasmic inclusion bodies in ciliated bronchial epithelium months to years after acute Kawasaki disease. PLoS One 2008;3:e1582. 